\title{
Predictors of parental distress during acute phase of pediatric hematopoietic stem cell transplantation in Japan: A multicenter prospective study
}

\author{
Shohei Nakajima ${ }^{1}$, Ami Setoyama1, Iori Sato ${ }^{1}$, Tomoko Fukuchi², Harumi Tanaka², Masami Inoue ${ }^{3}$, Kentaro Watanabe ${ }^{4}$, \\ Katsuyoshi Koh ${ }^{4}$, Junko Takita ${ }^{5}$, Mika Tokuyama ${ }^{6}$, Kenichiro Watanabe $^{6}$, Kiyoko Kamibeppu ${ }^{1}$ \\ ${ }^{1}$ Department of Family Nursing, Division of Health Sciences and Nursing, Graduate School of Medicine, The University \\ of Tokyo, Tokyo, Japan. \\ 2Department of Nursing, Osaka Women's and Children's Hospital, Osaka, Japan. \\ ${ }^{3}$ Department of Hematology/Oncology, Osaka Women's and Children's Hospital, Osaka, Japan. \\ ${ }^{4}$ Department of Hematology/Oncology, Saitama Children's Medical Center, Saitama, Japan. \\ ${ }^{5}$ Department of Pediatrics, The University of Tokyo Hospital, Tokyo, Japan. \\ ${ }^{6}$ Department of Hematology and Oncology, Shizuoka Children's Hospital, Shizuoka, Japan.
}

Abstract

Objective: The purposes of this study were (1) to describe the levels of anxiety and depressive symptoms in parents of children undergoing hematopoietic stem cell transplantation (HSCT) before (Time 1 [T1]) and one month after transplantation (Time 2 [T2]), and (2) to identify the pre-HSCT factors that predict anxiety and depressive symptoms in fathers and mothers one month after transplantation.

Methods: A prospective quantitative study was conducted at four children's hospitals between June 2015 and September 2016 using self-administered questionnaires and medical records. Parents from 23 families, including 19 fathers and 23 mothers, completed the Hospital Anxiety and Depression Scale (cutoff score: 8) and provided information regarding their stress appraisal, coping strategies, family functioning, demographic characteristics, and children's health-related quality of life. Hierarchical multiple regression analysis was performed to identify the variables that predicted T2 paternal and maternal anxiety and depressive symptoms.

Results: Among the parents, 15 fathers (79\%) and 11 mothers (48\%) reported anxiety symptoms, and 13 fathers (68\%) and 9 mothers (39\%) reported depressive symptoms above the cutoff level for clinical relevance at T1. Similarly, 11 fathers (58\%) and 6 mothers (26\%) reported anxiety symptoms, and 10 fathers (53\%) and 9 mothers (39\%) reported depressive symptoms above the cutoff level at T2. Overall, parents' anxiety and depressive symptoms did not differ significantly between T1 and T2. For fathers, both T1 depressive symptoms and the understanding of their children's medical situation through communication with other parents and consultation with medical staff predicted T2 paternal depressive symptoms. For mothers, T1 maternal anxiety symptoms and marital satisfaction predicted $\mathrm{T} 2$ anxiety symptoms.

Conclusions: The medical staff should understand that parents of children undergoing HSCT experience considerable psychological distress throughout the treatment process, and therefore, they should adopt unique approaches to reduce such distress.

Key words: Anxiety/depression, Family, Pediatric, Quantitative

Submitted October 18, 2018; Accepted April 15, 2019; Published online June 18, 2019; Issued online August 1, 2019

Correspondence: Kiyoko Kamibeppu, Department of Family Nursing, Division of Health Sciences and Nursing, Graduate School of Medicine, The University of Tokyo, 7-3-1, Bunkyo-ku, Tokyo 113-0033, Japan, E-mail: kkamibeppu-tky@umin.ac.jp

\section{Introduction}

Hematopoietic stem cell transplantation (HSCT) is an accepted therapy for numerous childhood diseases, including cancer. It involves conditioning, which combines high-dose chemotherapy and total body irradiation 
(TBI) and has been shown to increase survival rates ${ }^{1}$. In Japan, approximately 500 pediatric patients undergo HSCT annually ${ }^{2,3}$; however, some patients experience transplant-related complications, such as infection and graft-versus-host disease (GVHD) ${ }^{1,4}$, and spend several weeks in isolation to prevent infection caused by myelosuppression $^{5}$. Various psychological problems such as anxiety and depression ${ }^{5,6}$ are common during the acute phase of HSCT and reduce children's health-related quality of life (HRQOL $)^{5,7,8}$. Children who experience increased emotional disturbance before HSCT have been shown to exhibit post-traumatic stress disorder (PTSD) and poor HRQOL after HSCT ${ }^{5,9}$. Therefore, children's physical and psychological distress is most pronounced during the acute phase of HSCT and may affect them later in life.

Parents of pediatric HSCT patients are also affected by their children's illness ${ }^{10,11}$ and could experience psychological problems such as depression ${ }^{12-14}$, anxiety ${ }^{14}$, and adjustment disorder ${ }^{15}$. Phipps, Dunavant, Lensing, and Rai $^{16}$ conducted a longitudinal study and found that parents exhibited high psychological distress levels before their children's hospital admission, and this peaked approximately 2-3 weeks after HSCT. The trajectories of distress follow a similar pattern in children and their parents. Parental stress has been reported to be higher than the stress in the general population in relation to the HSCT process ${ }^{17}$. In addition, Manne et al. ${ }^{18}$ showed that parents, particularly mothers, who experienced depressive symptoms during the acute HSCT phase were more likely to be diagnosed with PTSD 18 months later than were those without depressive symptoms. Therefore, the most frequently identified risk factor for parental distress is whether parents can is the amount of stress the parents experience during the acute phase of $\mathrm{HSCT}^{11}$. Some longitudinal studies have investigated the predictors of parental psychological distress at 4-6 months ${ }^{16}$ and two years after $\mathrm{HSCT}^{19,20}$; however, no studies have examined the psychological predictors of parental distress during the acute phase of HSCT. In order to offer targeted prevention or interventions, families experiencing distress that might have a negative psychological effect on the parents, as well as children, need to be identified. For identifying these families, an understanding of the predictors of their distress ${ }^{12}$, particularly anxiety and depression, is required, and the time when distress levels are highest during treatment should be determined. Furthermore, an increasing number of studies have included mothers of children undergoing $\mathrm{HSCT}^{13-15,18}$ while few have focused on fathers; however, it is critical to understand both parents' experiences ${ }^{21}$.

In this study, we applied the transactional stress and coping model ${ }^{13,22}$, which is a framework for evaluating the processes of coping with stressful life events. This model indicates the processes associated with parental adjustment to pediatric illness and includes components of parents' pre-HSCT variables-specifically, (1) their cognitive processes (e.g., appraisal-stress, expectations), (2) methods of coping, and (3) perceptions of the family environment-as factors hypothesized to predict parental psychological outcomes. These three factors may mediate the relationship of the children's illness and demographic parameters with parental psychological distress; therefore, we hypothesized that they would predict psychological distress in our study. According to existing review articles examining parental psychosocial experiences, some factors varied according to the parent's sex (e.g., perceptions of marital or family functioning, coping strategies $)^{21}$. By understanding the predictors of both paternal and maternal psychological distress during the acute phase of HSCT, we may be able to identify and support highly distressed parents before HSCT and create new intervention methods for them and their children, focusing on the time interval preceding HSCT. The purposes of this study were (1) to describe the levels of anxiety and depressive symptoms in parents of children undergoing HSCT, before and one month after transplantation, and (2) to identify the pre-HSCT factors that predict anxiety and depressive symptoms in fathers and mothers one month after transplantation.

\section{Patients and Methods}

\section{Study design and participants}

A multicenter, prospective, quantitative study was conducted in four children's hospitals in Japan between June 2015 and September 2016 using self-administered questionnaires and medical records.

The participants were fathers and mothers with children aged between 2 and 18 years scheduled to undergo HSCT. The inclusion criteria were (1) parents' (either or both) provision of an informed consent and (2) the ability to understand Japanese and complete the questionnaires independently. We did not make any distinction based on the parents' marital status regarding which parents were invited to participate in this study. The exclusion criterion was unsuitability for participation due to the participant's physical or mental health, as determined by a pediatrician. The discontinuation criterion was difficulty participating in the study because of the child's death or transfer to an intensive care unit, as determined by a pediatrician.

\section{Procedure}

The date of hematopoietic stem cell infusion was selected as Day 0. Time 1（T1）was defined as the period from the day on which the pediatricians explained the HSCT procedures to the day before conditioning, and 
Time 2(T2) was defined as the period from Day 23 to 37.

Pediatricians recruited the participants, and the study was explained in easily understandable terms. If the parents agreed to participate, they received an explanation regarding the consent procedure and ethical considerations, along with an informed consent form. All participants provided a written informed consent and received the T1 questionnaires with their corresponding envelopes, a self-addressed stamped return envelope, and compensation (i.e., a gift certificate worth 9.00 USD). Participants completed the T1 questionnaires and placed them in the designated envelopes, which were then inserted into the self-addressed, stamped envelopes and mailed. Approximately 20 days after HSCT, participants received the T2 questionnaires and compensation equal to that of T1; they then completed the questionnaires and returned them via the same method used for the T1 questionnaire. The researchers or pediatricians obtained the participants' medical information from their medical records at each time point.

\section{Measurements}

\section{Anxiety and depressive symptoms}

Parental distress was measured at T1 and T2 using the Hospital Anxiety and Depression Scale (HADS) ${ }^{23}$. In this study, a symptom of anxiety was defined as continuous feelings of vague and undifferentiated fear, and a symptom of depression was defined as continuous states of sadness above the normal range. The HADS consists of 14 items divided between two subscales (i.e., symptoms of anxiety and depression), and respondents were required to indicate their levels of anxiety and depressive symptoms during the preceding week using a 4-point Likert scale ranging from 0 to 3 . Higher scores indicate greater psychological distress (range: 0-21; clinical cutoff point: 8 ). This scale has been used in a previous study ${ }^{24}$; its reliability and validity have been firmly established. Cronbach's alpha for the anxiety subscale was .73 (T1) and .85 (T2) for fathers and .79 (T1) and .85 (T2) for mothers; for the depression subscale, it was .79 (T1) and $.73(\mathrm{~T} 2)$ for fathers and .70（T1） and .82（T2） for mothers.

\section{Children's HRQOL}

Children's HRQOL was assessed by a parent-proxy report at T1, using the Pediatric Quality of Life Inventory $^{\mathrm{TM}}$ Generic Core Scales (PedsQL) ${ }^{25-28}$, which measure pediatric HRQOL during the preceding month. These questionnaires contain 21-23 items, and responses are provided using a 5-point Likert scale, which has demonstrated good reliability and validity. Higher scores indicate higher HRQOL levels in children, based on the Ped$\mathrm{sQL}$ scoring algorithm ${ }^{29}$. Cronbach's alpha for all domains exceeded 70 .

\section{Stress appraisal}

The Japan Perceived Stress Scale (JPSS) ${ }^{30}$ was used to assess the degree to which parents considered their lives as unpredictable, uncontrollable, and overwhelming. The scale consists of 14 items, with responses provided using a 5-point Likert scale ranging from 0 (never) to 4 (very often). Higher scores indicate greater perceived stress, which has demonstrated good reliability and validity. Cronbach's alpha was .79 for fathers and .73 for mothers.

\section{Coping strategies}

The Coping Health Inventory for Parents (CHIP) ${ }^{31}$ was used to assess parents' perception of their management of family life with a child with a chronic illness. The scale consists of 45 items divided between three coping patterns: maintaining family integration, cooperation, and an optimistic definition of the situation (Pattern 1); maintaining social support, self-esteem, and psychological stability (Pattern 2); and understanding the medical situation through communication with other parents and consultation with the medical staff(Pattern 3 ). This scale was adapted for parents of children with cancer. Items are rated on a scale from 0 (not helpful) to 3 (extremely helpful). Cronbach's alpha for all domains exceeded .80 for both parents.

\section{Family functioning}

The Family Adaptability, Partnership, Growth, Affection, and Resolve (APGAR) ${ }^{32}$ Scale and Material Love Scale $^{33}$ were used to assess the parents' perception of family functioning; both scales demonstrated good reliability and validity. The Family APGAR Scale assesses the family members' satisfaction with family relationships and includes five items. Responses are provided using a 3-point Likert scale ranging from 0 (hardly ever) to 2 (almost always), and higher scores indicate greater satisfaction with family functioning. The Material Love Scale consists of 16 items measuring assiduity, interest, understanding, respect, and support provided by partners in emotional relationships. Responses are provided using a 4-point Likert scale ranging from 1 (not always) to 4 (always). Higher scores indicate greater satisfaction with the marital relationship, longer conversation times, and greater self-disclosure. The Cronbach's alphas for both scales demonstrated good consistency (.79 to .96).

\section{Demographic and medical variables}

All parents provided their demographic characteristics, including age, marital status, health status, educational level, economic status, visiting hours, commuting time to the hospital, and occupation; family characteristics included family structure and the presence or absence of a related donor in their questionnaires.

We obtained information via medical records; specifically, (1) the children's demographic characteristics included sex and age, and (2) their medical characteristics including diagnosis, age at diagnosis, therapy evaluation 
before HSCT, performance status, types of stem cell and donor, conditioning regimen, radiation status (TBI or cranial radiation therapy and doses), types and routes of immunosuppression at T1, grade of acute GVHD, engraftment duration, and entry to a cleanroom at $\mathrm{T} 2$.

\section{Statistical analyses}

We calculated the descriptive statistics for the participants' scores at each time point and compared parental HADS scores between T1 and T2 using pairwise $t$-tests. In addition, we performed bivariate analyses $\left(\chi^{2}\right.$, Tukey's honestly significant difference test, or Spearman's rank correlation coefficient) to examine factors related to T2 parental anxiety and depressive symptoms. We also determined the correlations between paternal or maternal anxiety or depressive scores at each of the time points using Spearman's rank correlation.

Hierarchical multiple regression analysis was performed to explore $\mathrm{T} 1$ factors that predicted $\mathrm{T} 2$ anxiety and depressive symptoms in order to define the objective variables. Explanatory variables were entered as follows: in Step 1, T1 anxiety and depressive symptoms (HADS scores) were entered into the regression model simultaneously (Model 1). In Step 2, we entered two components; (1) total PedsQL scores based on the paternal or maternal perception, and (2) variables that were statistically significant in the bivariate analysis, in particular, ordinal scales with Spearman's rank correlation coefficients $(\rho)$ of >.40 (Model 2). In Step 3, parental stress appraisals, coping strategies, and family functioning items with Spearman's rank correlation coefficients $(\rho)$ of $>.40$ were entered using backward-elimination methods (Model 3), with consideration of Akaike's information criterion. All final models were verified via post hoc analysis using the coefficient of determination. Analyses were performed using R ver. 3.3.2 and the significance level was set at 5\% (two-tailed).

\section{Ethical considerations}

The study was approved by the ethics committee at the Graduate School of Medicine, The University of Tokyo (reference no. 10855), and the institutional review boards at the hospitals where the survey was conducted. A written informed consent was obtained from all participants in accordance with the latest version of the Helsinki Declaration. The researchers explained that the participants could withdraw from the study if they did not want to answer the questionnaires.

\section{Results}

\section{Participant flow and characteristics}

A total of 34 children underwent HSCT during the study period; four parents refused to participate because of the potential psychological burden, and 30 families agreed to participate in the study. Of these, 24 families completed the questionnaires; however, four fathers did not complete the T2 questionnaire. Attrition occurred because of children's deaths $(n=2)$, engraftment failure $(n=1)$, transfer to intensive care units $(n=1)$, and unknown reasons $(n=2)$. Additionally, one family with numerous missing values in the questionnaires was excluded; therefore, data from 23 families (19 fathers and 23 mothers) were ultimately analyzed (valid response rate: $67 \%$ ).

The children's mean age was 8.3 years (Table 1); 14 $(61 \%)$ children were boys; $6(26 \%)$ children had been diagnosed with acute lymphoblastic leukemia; and 14 $(61 \%)$ were hospitalized for HSCT. A total of $20(87 \%)$ children underwent allogeneic HSCT, and more than half of the donors were unrelated. In addition, 4 (17\%), 10 $(44 \%)$, and $9(39 \%)$ graft sources were the bone marrow, peripheral blood stem cells, and umbilical cord blood, respectively. Most conditioning regimens were non-myeloablative $(75 \%)$, and 7 children $(35 \%)$ received TBI. The probability of occurrence of acute GVHD was $20 \%$ to $30 \%$ depending on the organ involved. The mean number of days waiting for engraftment and living in a cleanroom were 14.8 and 16.0 , respectively.

The mean ages of the fathers and mothers were 41.3 and 38.3 years, respectively (Table 2). More than half of the parents reported a low economic status. The mothers visited their children more frequently than the fathers did, and 10 mothers $(44 \%)$ spent every day with their children during hospitalization. All fathers worked; however, more than half reported reduced working hours. Half of the mothers were employed, and half had retired or resigned from work following their child's diagnosis.

\section{Parental symptoms of anxiety and depression following HSCT}

Data on the parental HADS scores at each time point are presented in Table 2. Of the parents, 15 fathers $(79 \%)$ and 11 mothers $(48 \%)$ reported anxiety symptoms, and 13 fathers $(68 \%)$ and 9 mothers $(39 \%)$ reported depressive symptoms above the cutoff level for clinical relevance at T1. Similarly, 11 fathers $(58 \%)$ and 6 mothers $(26 \%)$ reported anxiety symptoms, and 10 fathers $(53 \%)$ and 9 mothers $(39 \%)$ reported depressive symptoms above the cutoff level at T2. The levels of anxiety and depressive symptoms did not differ significantly between T1 and T2 (paternal anxiety symptoms score: $P=.345$; paternal depressive symptoms score: $P=.201$; maternal anxiety symptoms score: $P=.191$; maternal depressive symptoms score: $P=.915)$. No significant correlations between paternal or maternal anxiety and depressive symptoms at each of the time points was noted. 
Table 1. Children's demographic and illness parameters $(n=23)$

\begin{tabular}{|c|c|c|c|}
\hline & $n($ & or mean $\pm S D$ & [range] \\
\hline \multirow[t]{2}{*}{ Sex } & Male & $14(61)$ & \\
\hline & Female & $9(39)$ & \\
\hline Age (years) & & $8.3 \pm 3.1$ & {$[2-14]$} \\
\hline \multirow[t]{6}{*}{ Diagnosis } & Acute lymphoblastic leukemia & $6(26)$ & \\
\hline & Acute myeloid leukemia & $3(13)$ & \\
\hline & Myelodysplastic syndrome & $3(13)$ & \\
\hline & Malignant Iymphoma & $3(13)$ & \\
\hline & Neuroblastoma & $3(13)$ & \\
\hline & Other & $5(22)$ & \\
\hline Age at diagnosis (years) & & $6.3 \pm 3.7$ & {$[0-13]$} \\
\hline \multirow[t]{2}{*}{ Performance status } & 0 & $20(87)$ & \\
\hline & $>1$ & $3(13)$ & \\
\hline \multirow[t]{3}{*}{ Type of HSCT } & Related allogeneic & $9(39)$ & \\
\hline & Unrelated allogeneic & $11(48)$ & \\
\hline & Autologous & $3(13)$ & \\
\hline \multirow[t]{3}{*}{ Recipient relationship with donor $(n=9)$} & Father & $1(11)$ & \\
\hline & Mother & $3(33)$ & \\
\hline & Sibling & $5(56)$ & \\
\hline \multirow[t]{3}{*}{ Graft source } & Bone marrow & $4(17)$ & \\
\hline & Peripheral blood stem cell & $10(44)$ & \\
\hline & Umbilical cord blood & $9(39)$ & \\
\hline \multirow[t]{2}{*}{ Conditioning $^{\dagger}$} & Myeloablative & $5(25)$ & \\
\hline & Non-myeloablative & $15(75)$ & \\
\hline \multirow[t]{3}{*}{ Total body irradiation $^{\dagger}$} & 12 Gy & $5(25)$ & \\
\hline & $2-4$ Gy & $2(10)$ & \\
\hline & None & $13(65)$ & \\
\hline \multirow[t]{2}{*}{ Immunosuppression $^{\dagger}$} & Tacrolimus & $18(90)$ & \\
\hline & Cyclosporine & $2(10)$ & \\
\hline \multirow[t]{3}{*}{ Acute GVHD (number above Grade 1$)^{\dagger}$} & Gut & $4(20)$ & \\
\hline & Liver & $4(20)$ & \\
\hline & Skin & $6(30)$ & \\
\hline Engraftment duration (days) & & $14.8 \pm 3.4$ & [10-24] \\
\hline Duration of cleanroom confinement (days) & & $16.0 \pm 4.2$ & [10-24] \\
\hline
\end{tabular}

${ }^{\dagger}$ Calculated for twenty allogeneic patients.

GVHD, graft-versus-host disease; HSCT, hematopoietic stem cell transplantation; SD, standard deviation.

\section{Pre-HSCT factors related to the parental symp- toms of anxiety and depression one-month post- HSCT}

In the bivariate analysis between $\mathrm{T} 2$ parental distress and pre-HSCT factors, T2 paternal anxiety symptoms were significantly associated with T1 paternal anxiety symptoms $(\rho=.71, P<.001)$, depressive symptoms $(\rho=$ $.60, P<.001)$, Material Love Scale scores $(\rho=-.54, P$ $=.018)$, and age $(\rho=-.46, P=.045)$. T2 paternal depressive symptoms were significantly associated with T1 paternal anxiety symptoms $(\rho=.57, P=.010)$, depressive symptoms $(\rho=.84, P<.001)$, CHIP Pattern $3(\rho=-$ $.70, P<.001)$, Family APGAR scores $(\rho=-.56, P=$ $.027)$, Material Love Scale scores $(\rho=-.56, P=.013)$, and maternal age $(\rho=-.47, P=.043)$. T2 maternal anxiety symptoms were significantly associated with $\mathrm{T} 1$ maternal anxiety symptoms $(\rho=.53, P=.010)$, CHIP
Pattern 2( $\rho=-.45, P=.033)$, Love Scale scores $(\rho=-$ $.51, P=.012)$, and economic status $(\rho=-.51, P=.014)$. T2 maternal depressive symptoms were significantly associated with T1 maternal anxiety symptoms $(\rho=.68$, $P<.001)$ and depressive symptoms $(\rho=.70, P<.001)$.

Only the mother's educational status was related to T2 maternal depressive symptoms; specifically, mothers with a college or university education reported significantly higher depressive symptoms than did mothers with a high school education (mean score differences $=4.4, t(21)=$ $-2.71, P=.013)$. Children's age, age at diagnosis, engraftment duration, and duration of cleanroom confinement did not correlate with parental distress. Other parental demographic information, children's demographic data, and illness parameters were not significantly associated with T2 parental anxiety or depressive symptoms, including the type of HSCT(i.e., autologous, related allogeneic, 
Table 2. Parents' demographic characteristics

\begin{tabular}{|c|c|c|c|c|c|c|c|}
\hline & \multicolumn{3}{|c|}{ Fathers $(n=19)$} & \multicolumn{3}{|c|}{ Mothers $(n=23)$} \\
\hline & & \multicolumn{3}{|c|}{$n(\%)$ or mean $\pm S D$ [range] } & \multicolumn{3}{|c|}{$n(\%)$ or mean $\pm S D$ [range] } \\
\hline & & \multicolumn{2}{|c|}{ Time 1} & Time 2 & \multicolumn{2}{|c|}{ Time 1} & \multirow[t]{2}{*}{ Time 2} \\
\hline Age (years) & & $41.3 \pm 5.0$ & {$[32-52]$} & & $38.3 \pm 5.3$ & {$[29-48]$} & \\
\hline Marital status & Married & $19(100)$ & & & $21(91)$ & & \\
\hline Health status & No health problems & $18(95)$ & & & $22(96)$ & & \\
\hline \multirow[t]{2}{*}{ Educational level } & Below high school & $7(37)$ & & & $10(43)$ & & \\
\hline & $\begin{array}{l}\text { Over College or } \\
\text { University }\end{array}$ & $12(63)$ & & & $13(57)$ & & \\
\hline \multirow[t]{5}{*}{ Economic status } & Very high & $0(0)$ & & & $0(0)$ & & \\
\hline & High & $3(15)$ & & & $0(0)$ & & \\
\hline & Average & $6(32)$ & & & $10(43)$ & & \\
\hline & Low & $6(32)$ & & & $10(43)$ & & \\
\hline & Very low & $4(21)$ & & & $3(14)$ & & \\
\hline \multirow[t]{2}{*}{ Visiting hours (hours) } & Weekdays & $2.9 \pm 3.7$ & {$[0-12]$} & & $14.6 \pm 9.7$ & {$[0-24]$} & \\
\hline & Weekends & $6.4 \pm 5.1$ & {$[0-18]$} & & $15.4 \pm 9.2$ & {$[0-24]$} & \\
\hline $\begin{array}{l}\text { Commuting time to } \\
\text { hospital (minutes) }\end{array}$ & & $96.8 \pm 99.6$ & {$[15-300]$} & & $87.3 \pm 102.8$ & {$[3-390]$} & \\
\hline \multirow[t]{4}{*}{ Employment status $^{\dagger}$} & Full-time & $16(84)$ & & & $5(22)$ & & \\
\hline & Part-time & $0(0)$ & & & $5(22)$ & & \\
\hline & Self-employed & $3(16)$ & & & $2(8)$ & & \\
\hline & Not working & $0(0)$ & & & $11(48)$ & & \\
\hline \multirow{4}{*}{$\begin{array}{l}\text { Changes in working } \\
\text { hours following } \\
\text { child's diagnosis }^{\dagger}\end{array}$} & Increased & $4(21)$ & & & 1 (8) & & \\
\hline & Unchanged & $5(26)$ & & & $1(8)$ & & \\
\hline & Decreased & $10(53)$ & & & $4(34)$ & & \\
\hline & $\begin{array}{l}\text { Leave of absence/ } \\
\text { Retirement }\end{array}$ & $0(0)$ & & & $6(50)$ & & \\
\hline $\begin{array}{l}\text { HADS Anxiety score } \\
\text { [range: } 0-21 \text { ] }\end{array}$ & & $9.3 \pm 3.6$ & {$[2-17]$} & $9.2 \pm 3.9 \quad[3-15]$ & $8.1 \pm 3.3$ & [3-15] & $7.0 \pm 3.8 \quad[1-15]$ \\
\hline $\begin{array}{l}\text { HADS Depression } \\
\text { score [range: } 0-21]\end{array}$ & & $8.2 \pm 3.8$ & {$[1-15]$} & $7.6 \pm 3.6 \quad[1-15]$ & $6.9 \pm 2.9$ & {$[1-14]$} & $6.9 \pm 4.5 \quad[0-15]$ \\
\hline PedsQL & $\begin{array}{l}\text { Total score [range: } \\
\text { 0-100] }\end{array}$ & $66.4 \pm 14.7$ & {$[47-99]$} & & $76.4 \pm 14.6$ & {$[49-97]$} & \\
\hline JPSS [range: 0-56] & & $26.6 \pm 7.1$ & {$[5-35]$} & & $26.9 \pm 5.5$ & [13-37] & \\
\hline \multirow[t]{3}{*}{$\mathrm{CHIP}$} & $\begin{array}{l}\text { Pattern } 1 \text { [range: } \\
\text { 0-57] }\end{array}$ & $25.2 \pm 10.3$ & {$[0-40]$} & & $29.9 \pm 8.8$ & {$[0-47]$} & \\
\hline & $\begin{array}{l}\text { Pattern } 2 \text { [range: } \\
\text { 0-54] }\end{array}$ & $14.4 \pm 8.5$ & [0-32] & & $17.1 \pm 9.4$ & {$[0-42]$} & \\
\hline & $\begin{array}{l}\text { Pattern } 3 \text { [range: } \\
\text { 0-24] }\end{array}$ & $11.0 \pm 6.1$ & {$[0-21]$} & & $16.9 \pm 5.2$ & {$[0-26]$} & \\
\hline $\begin{array}{l}\text { Family APGAR Scale } \\
\text { [range: } 0-10 \text { ] }\end{array}$ & & $7.2 \pm 3.1$ & {$[0-10]$} & & $7.4 \pm 2.4$ & [3-10] & \\
\hline $\begin{array}{l}\text { Love Scale [range: } \\
1-4 \text { ] }\end{array}$ & & $3.1 \pm 0.7$ & {$[1.0-3.9]$} & & $3.0 \pm 0.6$ & {$[1.6-4.0]$} & \\
\hline
\end{tabular}

Missing values were excluded; ${ }^{\dagger}$ Calculated for employed parents.

CHIP, Coping Health Inventory for Parents; HADS, Hospital Anxiety and Depression Scale; JPSS, Japanese Perceived Stress Scale; Ped$\mathrm{sQL}$, Pediatric Quality of Life Inventory ${ }^{\mathrm{TM}}$ Generic core scales total score; SD, standard deviation.

or unrelated allogeneic; see Table 3).

Table 4 shows the hierarchical multiple regression models for predictors of parents' T2 anxiety and depressive symptoms. T1 paternal depressive symptoms $(\beta=$ $.61, P=.014)$ and CHIP pattern $3(\beta=-.86, P$.049) predicted T2 paternal depressive symptoms, considering mediational factors. T1 maternal anxiety symptoms ( $\beta=$ $.65, P=.047)$ and Love Scale scores $(\beta=-.52, P=$
.013) predicted T2 maternal anxiety symptoms. T1 paternal anxiety symptoms predicted $\mathrm{T} 2$ paternal anxiety symptoms; however, this effect was mediated by other factors. T1 maternal depressive symptoms predicted T2 maternal depressive symptoms, but this effect was mediated by individual factors; all mediating factors were removed in the final model. 


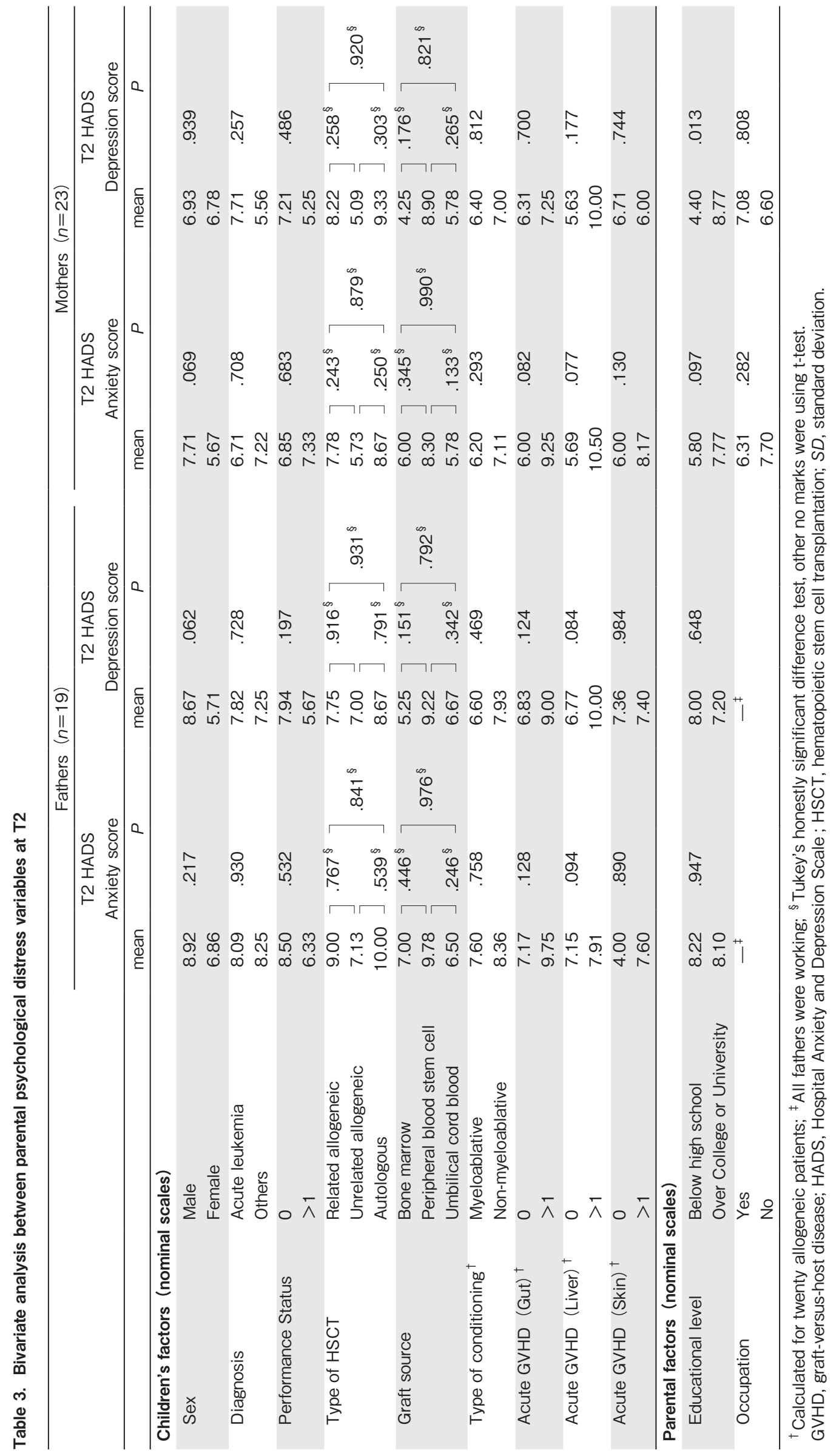


Table 4. Hierarchical multiple regression analysis of predictors of parental psychological distress at T2 (1 month after HSCT)

\begin{tabular}{|c|c|c|c|c|c|c|c|c|c|}
\hline & \multicolumn{3}{|c|}{ Model 1} & \multicolumn{3}{|c|}{ Model 2} & \multicolumn{3}{|c|}{ Model 3} \\
\hline & $\beta$ & SE & $P$ & $\beta$ & SE & $P$ & $\beta$ & SE & $P$ \\
\hline \multicolumn{10}{|l|}{ Paternal anxiety symptoms $(n=19)$} \\
\hline HADS Anxiety score (T1) & 0.57 & 0.22 & .019 & 0.54 & 0.25 & .046 & 0.32 & 0.24 & .221 \\
\hline HADS Depression score (T1) & 0.27 & 0.22 & .238 & 0.23 & 0.23 & .351 & 0.14 & 0.21 & .503 \\
\hline Paternal Age & & & & -0.14 & 0.20 & .492 & -0.13 & 0.18 & .481 \\
\hline Total PedsQL score & & & & 0.01 & 0.19 & .953 & 0.08 & 0.19 & .672 \\
\hline JPSS score & & & & & & & 0.31 & 0.22 & .179 \\
\hline Love Scale score & & & & & & & -0.33 & 0.16 & .065 \\
\hline$R^{2}$ & 0.60 & 0.67 & $<.001$ & 0.62 & 0.70 & .007 & 0.76 & 0.61 & .004 \\
\hline adjusted $R^{2}$ & 0.55 & & & 0.51 & & & 0.63 & & \\
\hline \multicolumn{10}{|l|}{ Paternal depressive symptoms $(n=19)$} \\
\hline HADS Anxiety score $(\mathrm{T} 1)$ & -0.02 & 0.19 & .913 & -0.06 & 0.20 & .762 & -0.31 & 0.23 & .205 \\
\hline HADS Depression score (T1) & 0.85 & 0.19 & $<.001$ & 0.79 & 0.19 & .001 & 0.61 & 0.21 & .014 \\
\hline Paternal Age & & & & -0.21 & 0.17 & .216 & -0.15 & 0.16 & .363 \\
\hline Total PedsQL score & & & & 0.02 & 0.15 & .874 & -0.23 & 0.21 & .307 \\
\hline CHIP Pattern 1 & & & & & & & 0.62 & 0.31 & .075 \\
\hline CHIP Pattern 3 & & & & & & & -0.86 & 0.38 & .049 \\
\hline JPSS & & & & & & & 0.29 & 0.21 & .188 \\
\hline \multirow[t]{3}{*}{ Love Scale score } & & & & & & & -0.21 & 0.15 & .182 \\
\hline & 0.70 & 0.58 & $<.001$ & 0.74 & 0.57 & $<.001$ & 0.84 & 0.53 & .003 \\
\hline & 0.66 & & & 0.67 & & & 0.72 & & \\
\hline \multicolumn{10}{|l|}{ Maternal anxiety symptoms $(n=23)$} \\
\hline HADS Anxiety score (T1) & 0.34 & 0.32 & .291 & 0.30 & 0.29 & .318 & 0.65 & 0.30 & .047 \\
\hline HADS Depression score (T1) & 0.22 & 0.32 & .490 & 0.13 & 0.31 & .680 & -0.18 & 0.31 & .564 \\
\hline Economic status & & & & -0.38 & 0.18 & .045 & -0.17 & 0.18 & .343 \\
\hline Total PedsQL score & & & & -0.28 & 0.19 & .153 & -0.29 & 0.17 & .119 \\
\hline \multirow[t]{3}{*}{ Love Scale score } & & & & & & & -0.52 & 0.19 & .013 \\
\hline & 0.29 & 0.88 & .033 & 0.47 & 0.81 & .018 & 0.63 & 0.71 & .007 \\
\hline & 0.22 & & & 0.35 & & & 0.50 & & \\
\hline \multicolumn{10}{|l|}{ Maternal depression symptoms $(n=23)$} \\
\hline HADS Anxiety score (T1) & 0.24 & 0.25 & .362 & 0.12 & 0.27 & .677 & & & \\
\hline HADS Depression score ( $\mathrm{T} 1)$ & 0.54 & 0.25 & .047 & 0.55 & 0.27 & .058 & & & \\
\hline Educational status & & & & 0.25 & 0.19 & .201 & & & \\
\hline Total PedsQL score & & & & 0.03 & 0.18 & .875 & & & \\
\hline$R^{2}$ & 0.54 & 0.71 & $<.001$ & 0.59 & 0.71 & .002 & & & \\
\hline adjusted $R^{2}$ & 0.50 & & & 0.04 & & & & & \\
\hline
\end{tabular}

Missing values are excluded; bold font indicates statistically significance.

$\beta$, standardized partial regression coefficient; CHIP, Coping Health Inventory for Parents; Family APGAR, Adaptability, Partnership, Growth, Affection, and Resolve; HADS, Hospital Anxiety and Depression Scale; JPSS, Japanese Perceived Stress Scale; PedsQL, Pediatric Quality of Life Inventory ${ }^{\mathrm{TM}}$ Generic core scales; $R^{2}$, coefficient of determination; SE, standard error.

\section{Discussion}

This study examined the levels of anxiety and depressive symptoms in parents immediately before and one month after their children underwent HSCT. The levels of anxiety and depressive symptoms were higher at T1 than at T2; however, this difference was not significant. We found that the predictors of $\mathrm{T} 2$ parental distress were different between fathers and mothers: T1 paternal depressive symptoms and understanding of the medical situation through communication with other parents and consultation with medical staff predicted T2 paternal depressive symptoms, while T1 maternal anxiety symptoms and satisfaction with their marital relationship predicted T2 maternal anxiety symptoms.

\section{Participants' demographic characteristics}

The parents' mean age was approximately 40 years; this was consistent with the findings of previous studies in which parents were in their late 30 s to early $40 \mathrm{~s}^{19,20,24}$. Regarding employment, Okada et al. ${ }^{34}$ reported that $80 \%$ of parents who were employed at the time of their children's cancer diagnosis resigned from work; this finding is consistent with the current study, where $50 \%$ of mothers retired or resigned from their job. In contrast, most fathers did not resign from work but reduced their work- 
ing hours. However, self-employed fathers increased their working hours. Moreover, parents of children with cancer experience significant psychological distress ${ }^{21}$; therefore, its management should include an assessment of not only parental attendance but also the parental role and employment status of both parents.

\section{Changes in parents' psychological distress levels following HSCT}

The parents' T1 psychological levels were higher than the corresponding T2 levels, but these differences were nonsignificant. This is consistent with the findings of a previous research, showing that parental distress was highest before the children's hospital admission ${ }^{21} \mathrm{~A}$ cross-sectional study involving 114 fathers and 146 mothers of children receiving HSCT measured HADS scores 5.5 years after treatment ${ }^{24}$ and found that $23 \%$ of fathers and $41 \%$ of mothers reported anxiety symptoms above the cutoff level for clinical relevance, and $15 \%$ of fathers and $22 \%$ of mothers reported depressive symptoms. These proportions are lower than those observed in the current study. In addition, a higher proportion of parents reported anxiety and depressive symptoms in the current study relative to those observed in a study that verified the reliability and validity of the HADS for use with the general Japanese population ${ }^{35}$ No previous studies have focused on the parents' psychological distress using HADS in Japan. In a cross-sectional study ${ }^{36}$ in the Netherlands focusing on the parents of children with chronic illnesses, the mothers' mean anxiety and depression scores were $5.9 \pm 4.1$ and $4.5 \pm 4.0$, respectively; the fathers' mean anxiety and depression scores were $4.8 \pm$ 4.4 and $4.5 \pm 4.2$, respectively. The above anxiety and depression scores are much lower than those found in the present study. Therefore, healthcare providers should be mindful of the fact that parental anxiety and depression levels may remain high throughout the HSCT process, and an appropriate assessment should be conducted before HSCT initiation if required.

\section{Pre-HSCT factors related to T2 parental anxiety and depressive symptoms}

Parental T1 depressive symptoms and understanding of the medical situation through communication with other parents and consultation with medical staff predicted $\mathrm{T} 2$ paternal depressive symptoms. In addition, all fathers in the study were employed and visited their children less frequently than did the mothers. In a previous study, CHIP Pattern 3 scores in fathers of children with a chronic illness were significantly lower than the mothers' scores; the reason for this finding could be that in most Japanese families, fathers work full-time, while mothers are responsible for taking care of the children ${ }^{31}$. Fathers have more difficulty seeking and receiving social support compared with mothers and are more likely to want to understand their children's illnesses ${ }^{21}$; therefore, the medical staff should explain the treatments and complications to the fathers before initiating the children's HSCT, acknowledge that the fathers might wish to connect with families of other children receiving HSCT, and provide peer support to reduce the fathers' psychological distress during the acute phase of HSCT.

$\mathrm{T} 1$ anxiety symptoms and satisfaction with the marital relationship predicted $\mathrm{T} 2$ maternal anxiety symptoms. A previous study found that mothers were less satisfied than the fathers because of an increase in housework and financial problems following their children's cancer diagnosis ${ }^{37}$. According to a previous study on the psychological adaptation of parents of pediatric cancer patients, mothers who adjusted well psychologically received more support and were less dissatisfied than were mothers who remained clinically distressed ${ }^{38}$; therefore, marital social support was found to be an important factor in reducing maternal distress. Additionally, mothers tended to use engaged and emotion-focused coping strategies ${ }^{21}$, and thus, providing emotional acceptance and empathic understanding to mothers regarding not only children's treatment but also their family relationships might reduce these symptoms of anxiety during the acute phase of HSCT.

\section{Implications for clinical practice and psychosocial providers}

Medical professionals should evaluate parental psychological distress during the HSCT process, particularly before initiating HSCT. The HADS could be used to screen and assess parental distress and to help medical professionals understand that the sources of paternal and maternal distress during HSCT might differ. Further, we should identify parents with high levels of anxiety and depressive symptoms throughout the HSCT process, and interventions to reduce their distress should be varied according to sex, considering their coping style and family relationships.

In addition, the children's characteristics were not significantly associated with $\mathrm{T} 2$ parental distress. This finding was consistent with the finding of a previous study ${ }^{13}$, according to which maternal depressive symptoms were not related to type of HSCT and degree of match HLA. Medical professionals should expect parents of children with severe symptoms (e.g., myeloablative conditioning and ongoing recurrence) to experience higher psychological distress levels than would those with children who have less severe conditions. Therefore, medical staff and psychosocial providers should understand the parents' unique experience and manage their psychological distress accordingly. 


\section{Limitations}

The study had three limitations. First, approximately $20 \%$ of the families withdrew from the study. In previous studies, transfer to an intensive care unit ${ }^{13}$ and high-risk treatment $^{39}$ increased anxiety and depressive symptoms in parents of children receiving HSCT; therefore, some drop-out parents might have felt severe psychological distress. Second, the sample size was relatively small, which could reduce the likelihood of identifying significant relationships in the data regarding predictor variables due to the limited power. Future studies should analyze paired parental data using methods such as multilevel analysis, which might help identify families who experience distress during their children's HSCT. Third, the study may not have captured the peak T2 parental psychological distress. The mean engraftment duration was 14.8 days, and we could not examine the parents' anxiety and depression levels when their children's physical problems were at their worst (e.g., when children experienced an engraftment syndrome or acute GVHD). Future studies should consider the predictors of parental distress using longitudinal surveys conducted within shorter periods, such as soon after engraftment (e.g., within one week).

\section{Acknowledgments}

We appreciate the contribution of the families who participated in the research and are grateful to all medical professionals at the collaborating institutions. This study was supported by a Grant-in-Aid for Pediatric Cancer Treatment and Research from the Children's Cancer Association of Japan 2015 and a JSPS KAKENHI grant (number JP26293469).

\section{Author's Contribution}

S. N. contributed to the conception/design of the study, data collection, data analysis, and drafting of the manuscript; T. F., H. T., M. I., K. W., K. K., J. T., M. T., and $\mathrm{K}$. W. participated in the study design, data collection, and critical revision of the manuscript; A. S., and I. S. participated in the study design, and critical revision of the manuscript; K. K. supervised the entire study process and critically reviewed the manuscript. All authors read and approved the final manuscript.

\section{Financial Support}

This study was supported by a Grant-in-Aid for Pediatric Cancer Treatment and Research from the Children's Cancer Association of Japan 2015 as well as a JSPS KAKENHI grant (number JP26293469).

\section{Conflicts of Interest}

The authors declare no conflict of interest. Disclosure forms provided by the authors are available here.

\section{References}

1. Copelan EA. Hematopoietic stem-cell transplantation. New Engl J Med. 2006; 354: 1813-26.

2. Horibe K, Tsuchida M, Tsurusawa M, Nakahata T. The realities of the medical system for pediatric hematologic malignancies in Japan. J Jpn Pediatr Soc. 2009; 113: 105-11 (in Japanese).

3. The Japanese Data Center for Hematopoietic Cell Transplantation. Activities and outcomes of hematopoietic cell transplantation in Japan (2018) . http: //www.jdchct.or.jp/en/data/slide/ 2018/[Published 2019. Updated Feb 1, 2019. Accessed Mar 4, 2019].

4. Knight JM, Lyness JM, Sahler OJZ, Liesveld JL, Moynihan JA. Psychosocial factors and hematopoietic stem cell transplantation: potential biobehavioral pathways. Psychoneuroendocrinology. 2013; 38: 2383-93.

5. Packman W, Weber S, Wallace J, Bugescu N. Psychological effects of hematopoietic SCT on pediatric patients, siblings and parents: a review. Bone Marrow Transplant. 2010; 45: 113446.

6. Chang G, Ratichek SJ, Recklitis C, Syrjala K, Patel SK, Harris $\mathrm{L}$, et al. Children's psychological distress during pediatric HSCT: parent and child perspectives. Pediatr Blood Cancer 2012; 58: 289-96.

7. Felder-Puig R, di Gallo A, Waldenmair M, Norden P, Winter A, Gadner H, et al. Health-related quality of life of pediatric patients receiving allogeneic stem cell or bone marrow transplantation: results of a longitudinal, multi-center study. Bone Marrow Transplant. 2006; 38: 119-26.

8. Phipps S, Dunavant M, Garvie PA, Lensing S, Rai SN. Acute health-related quality of life in children undergoing stem cell transplant: I. descriptive outcomes. Bone Marrow Transplant. 2002; 29: 425-34.

9. Parsons SK, Shih M, DuHamel KN, Ostroff J, Mayer DK, Austin J, et al. Maternal perspectives on children's health-related quality of life during the first year after pediatric hematopoietic stem cell transplant. J Pediatr Psychol. 2006; 31: 1100-15.

10. Lindwall JJ, Russell K, Huang Q, Zhang H, Vannatta K, Barrera $\mathrm{M}$, et al. Adjustment in parents of children undergoing stem cell transplantation. Biol Blood Marrow Transplant. 2014; 20: 543-48.

11. Vrijmoet-Wiersma CM, Egeler RM, Koopman HM, Norberg AL, Grootenhuis MA. Parental stress before, during, and after pediatric stem cell transplantation: a review article. Support Care Cancer. 2009; 17: 1435-43.

12. Jobe-Shields L, Alderfer MA, Barrera M, Vannatta K, Currier JM, Phipps S. Parental depression and family environment predict distress in children before stem cell transplantation. J Dev 
Behav Pediatr. 2009; 30: 140-6.

13. Manne, S., Duhamel, K., Ostroff, J., Parsons S, Martini DR, Williams SE, et al. Coping and the course of mother's depressive symptoms during and after pediatric bone marrow transplantation. J Am Acad Child Psy. 2003; 42: 1055-68.

14. Manne S, Nereo N, DuHamel K, Ostroff J, Parsons S, Martini $\mathrm{R}$, et al. Anxiety and depression in mothers of children undergoing bone marrow transplant: symptom prevalence and use of the Beck Depression and Beck Anxiety Inventories as screening instruments. J Consult Clin Psych. 2001; 69: 1037-47.

15. DuHamel KN, Manne S, Nereo N, Ostroff J, Martini R, Parsons $\mathrm{S}$, et al. Cognitive processing among mothers of children undergoing bone marrow/stem cell transplantation. Psychosom Med. 2004; 66: 92-103.

16. Phipps S, Dunavant M, Lensing S, Rai SN. Psychosocial predictors of distress in parents of children undergoing stem cell or bone marrow transplantation. J Pediatr Psychol. 2005; 30: 139-53.

17. Streisand R, Rodrigue JR, Houck C, Graham-Pole J, Berlant N. Brief report: parents of children undergoing bone marrow transplantation: documenting stress and piloting a psychological intervention program. J Pediatr Psychol. 2000; 25: 331-7.

18. Manne S, DuHamel K, Ostroff J, Parsons S, Martini DR, Williams SE, et al. Anxiety, depressive, and posttraumatic stress disorders among mothers of pediatric survivors of hematopoietic stem cell transplantation. Pediatrics. 2004; 113: 1700-8.

19. Barrera M, Atenafu E, Doyle J, Berlin-Romalis D, Hancock K. Differences in mothers' and fathers' health-related quality of life after pediatric SCT: a longitudinal study. Bone Marrow Transplant. 2011; 47: 855-9.

20. Barrera M, Atenafu E, Doyle J, Berlin-Romalis D, Hancock K. Differences in mothers' and fathers' psychological distress after pediatric SCT: a longitudinal study. Bone Marrow Transplant. 2011; 47: 934-9.

21. Clarke NE, McCarthy MC, Downie P, Ashley DM, Anderson VA. Gender differences in the psychosocial experience of parents of children with cancer: a review of the literature. Psychooncology. 2009; 18: 907-15.

22. Thompson R, Gill KM, Burbach DJ, Keith BR, Kinney TR. Psychological adjustment of mothers of children and adolescents with sickle cell disease: the role of stress, coping methods, and family functioning. J Pediatr Psychol. 1993; 18: 54959.

23. Zigmond AS, Snaith RP. The Hospital Anxiety and Depression Scale. Acta Psychiat Scand. 1983; 67: 361-70.

24. Riva R, Forinder U, Arvidson J, Mellgren K, Toporski J, Winiarski J, et al. Patterns of psychological responses in parents of children that underwent stem cell transplantation. Psychooncology. 2014; 23: 1307-13.

25. Kobayashi K, Kamibeppu K. Measuring quality of life in Japanese children: development of the Japanese version of PedsQL. Pediatr Int. 2010; 52: 80-8.

26. Varni JW, Burwinkle TM, Katz ER, Meeske K, Dickinson P. The PedsQL ${ }^{\mathrm{TM}}$ in pediatric cancer: reliability and validity of the Pediatric Quality of Life Inventory ${ }^{\mathrm{TM}}$ generic core scales, multidimensional fatigue scale, and cancer module. Cancer. 2002; 94: 2090-106.

27. Varni JW, Seid M, Kurtin PS. PedsQL 4.0: Reliability and validity of the Pediatric Quality of Life Inventory version 4.0 generic core scales in healthy and patient populations. Med Care. 2001; 39: 800-12.

28. Varni JW, Seid M, Rode CA. The PedsQL: measurement model for the Pediatric Quality of Life Inventory. Med Care. 1999; 37: 126-39.

29. Varni JW (2017). The PedsQL ${ }^{\mathrm{TM}}$ Scoring Algorithm: Scoring the Pediatric Quality of Life Inventory ${ }^{\mathrm{TM}}$. https: //www.pedsql. org/score.html [Published 2017. Updated Feb 8, 2017. Accessed Mar 4, 2019].

30. Mimura C, Griffiths P. A Japanese version of the Perceived Stress Scale: cross-cultural translation and equivalence assessment. BMC Psychiatry. 2008; 8: 85.

31. Nishio A. Parental psychological variation and support rearing children with cancer. Jpn J Child Nurs. 2006; 29: 1713-9（in Japanese).

32. Kokubu M, Kamibeppu K. Development of a "family functioning scale”: the Japanese version of Family APGAR. Principal researcher Kamibeppu K. The establishment of the family nursing technique and construction of the medical cooperation system model to realize the abuse prevention from the perinatal period: working report of grant in aid for scientific research in 2009-2011. 2013; 34. [Abstract] (in Japanese).

33. Ito Y, Sagara J. Reliability and validity of the Material Love Scale in middle-aged and elderly couples. Jpn Psychol Res. 2012; 83: 211-6 (in Japanese).

34. Okada H, Maru M, Maeda R, Iwasaki F, Nagasawa M, Takahashi M. Impact of childhood cancer on maternal employment in Japan. Cancer Nurs. 2015; 38: 23-30.

35. Hatta H, Higashi A, Yashiro H, Ozasa K, Hayashi K, Kiyota K, et al. Hospital Anxiety and Depression Scale: a validation of the Hospital Anxiety and Depression Scale. Jpn Soc Psychosom Med. 1998; 38: 309-15 (in Japanese).

36. van Oers HA, Haverman L, Limperg PF, van Dijk-Lokkart EM, Maurice-Stam H, Grootenhuis MA. Anxiety and depression in mothers and fathers of a chronically Ill child. Matern Child Health J. 2014; 18: 1993-2002.

37. Yeh $\mathrm{CH}$. Gender differences of parental distress in children with cancer. J Adv Nurs. 2002; 38: 598-606.

38. Hoekstra-Weebers JE, Jaspers JP, Kamps WA, Klip EC. Psychological adaptation and social support of parents of pediatric cancer patients: a prospective longitudinal study. J Pediatr Psychol. 2001; 26: 225-35.

39. DuHamel KN, Rini C, Austin J, Ostroff J, Parsons S, Martini R, et al. Optimism and life events as predictors of fear appraisals in mothers of children undergoing hematopoietic stem cell transplantation. Psychooncology. 2007; 16: 821-33.

https: //doi.org/10.31547/bct-2018-010 Copyright (C) 2019 APBMT. All Rights Reserved. 